ALTERIDADES, 2020, 30 (60): Págs. 51-65 www.doi.org/ $10.24275 / \mathrm{uam} / \mathrm{izt} / \mathrm{dcsh} / \mathrm{alt} / 2020 v 30 n 60 /$ Peters

\title{
Espacios culturales y museos bajo el estallido social de octubre de 2019 en Chile: experiencias, lecciones y proyecciones*
}

\author{
Cultural spaces and museums \\ under the October 2019 Chilean social boom: \\ experiences, lessons, and projections
}

TOMÁS PETERS**

\begin{abstract}
This article analyses how museums and cultural centers based close to the "zone O" of the Chilean Spring of 2019-2020, responded in its organizational operability and decision-making during the first months (from 18 October 2019 until February 2020). Considered as public and cultural deliberative spheres, this article analyses how these organizations acted during the development of the marches, protests and events of the revolt in its territories and communities. In doing so, this research developed a number of semi-structured interviews (N: 13) to members of the museums and cultural centers based in the more conflictive and violent area. The results show that the museums and cultural centers with public and hierarchical dependency tended to stablish a distant relationship during the Chilean Spring, meanwhile the privates and independent ones promoted a territorial link as well as a collaborative and creative one with the protesters and contingent communities.
\end{abstract}

Key words: Chilean Spring, public sphere, cultural centers, museums, territory

\section{Resumen}

Este artículo analiza cómo los museos y espacios culturales aledaños a la zona cero del estallido social de octubre de 2019 en Chile respondieron en su operatividad organizacional y toma de decisiones durante los primeros meses (18 de octubre de 2019 a febrero de 2020). Consideradas como esferas públicas y culturales deliberativas, este artículo examina cómo estas organizaciones actuaron frente al desarrollo de las marchas, protestas y acontecimientos de la revuelta en sus territorios y comunidades. Para ello, se realizaron entrevistas semiestructuradas a trece encargadas/os de los espacios culturales y museos alojados en el área de mayor conflicto y violencia. Los resultados demuestran que los museos y espacios culturales de dependencia pública tendieron a establecer una mayor distancia frente al estallido social, mientras que los independientes y privados promovieron un vínculo tanto territorial como colaborativo y creativo con los manifestantes y comunidades contingentes.

Palabras clave: estallido social, esfera pública, espacios culturales, museos, territorio

\footnotetext{
* Artículo recibido el 27/03/20 y aceptado el 08/05/20.

** Universidad de Chile, Instituto de la Comunicación e Imagen. Avenida Capitán Ignacio Carrera Pinto 1045, Ñuñoa, Región Metropolitana, Chile <tpeters@uchile.cl>. ORCID: 0000-0002-0765-917X.
} 


\section{Introducción}

$\mathrm{E}$ 118 de octubre de 2019 se ha inscrito en la historia reciente de Chile como el día que se inició el estallido social. Desde ese día se desencadenaron actos de violencia urbana, saqueos a tiendas y comercios, desobediencia civil, ataques incendiarios a bienes públicos y otros hechos caracterizados por la rebelión social. La respuesta política no se dejó esperar. Mediante decretos y acciones de fuerza, el gobierno encabezado por Sebastián Piñera dio paso a una militarización del país y a la restricción de las garantías constitucionales, lo que tuvo como consecuencia un número indeterminado de actos de violaciones a los derechos humanos por parte de agentes del Estado, así como también una acelerada ola de hechos de violencia en el país en respuesta al actuar político del gobierno.

Ese día, sin embargo, es el resultado de una historia mayor. El malestar ciudadano frente a una serie de prácticas sistemáticas de abusos, exclusión social y distribución desigual de la riqueza-una desigualdad estructural naturalizada-, se había acumulado por años en las estructuras de sentimiento de las / os chilenos. Las manifestaciones de la crisis habían sido evidentes desde hace años. Lo que ocurrió en la semana del 14 al 18 de octubre fue la exposición explícita de una lucha histórica, liderada por estudiantes secundarios, por radicalizar las contradicciones sociales, económicas y culturales de un modelo neoliberal instaurado por la fuerza durante la dictadura militar de Augusto Pinochet. Si bien las movilizaciones de esa semana surgieron por el alza del valor del boleto de metro, lo cierto es que pueden comprenderse por una acumulación histórica de frustración y rabia. La recuperación democrática en 1990 construyó un imaginario nacional sustentado por el éxito económico que, luego de treinta años de políticas de fomento empresarial y financiero, llevó a Chile a ser considerado uno de los países con la mayor desigualdad social del mundo.

A partir del 18 de octubre, Chile experimentó todos los días marchas, movilizaciones y actos de violencia, concentrándose en especial en las principales ciudades del país, pero sobre todo en la Plaza Italia, renombrada por las / os ciudadanos como Plaza de la Dignidad. Esta plaza, lugar tradicional de celebraciones deportivas y políticas, se convirtió en la zona cero del estallido social. En sus alrededores, durante cinco meses se confrontaron diariamente carabineros y militares con manifestantes, ciudadanos y "encapuchados" -también conocidos como "la primera línea": aquellos que enfrentan de manera directa a la fuerza pública. Como secuela de esto, no sólo se produjo un deterioro total del entorno urbano -literalmente se transformó en un campo de batalla-, sino también en las lógicas de desplazamiento y uso del espacio público. Al igual que negocios, restaurantes, bancos y servicios públicos, los museos y espacios culturales vieron afectados su funcionamiento y misión en esa zona. El presente artículo se propone explorar y analizar cómo los museos y espacios culturales aledaños a la zona cero respondieron en su operatividad y programación cultural durante los primeros meses del estallido social. En específico, lo que busca dilucidar es cómo estos espacios, considerados esferas públicas y culturales deliberativas, actuaron frente al desarrollo de las marchas, protestas y acontecimientos de la revuelta en sus territorios. Dentro de la delimitación geográfica de la zona cero se identificaron 19 espacios culturales y se entrevistó a trabajadores, representantes o directivos de 13 de ellos entre marzo y abril de 2020. Los resultados demuestran que los museos y espacios culturales de dependencia jerárquica pública tendieron a establecer una mayor distancia frente al estallido social, mientras que los independientes y privados promovieron un vínculo territorial y colaborativo con los manifestantes y comunidades contingentes.

Este texto expone, en primer lugar, las principales tesis y diagnósticos esbozados para "explicar" la emergencia del estallido social de Chile en octubre de 2019. A continuación, se analizan los espacios culturales y museos como esferas públicas y culturales deliberativas. Después se alude brevemente a la metodología de la investigación y, a continuación, se examinan los principales hallazgos del estudio a partir de seis dimensiones de análisis: 1) acciones inmediatas-contingentes al inicio del estallido; 2) vínculos de apoyo y protección institucional-pública al espacio; 3) relaciones laborales internas y cambios organizacionales; 4) vínculos entre manifestantes, públicos y comunidad del espacio durante el estallido (comunidades contingentes); 5) uso y estrategia comunicacional del espacio cultural; y 6) imaginarios y perspectivas futuras de los espacios culturales posestallido. Por último, se elaboran algunas líneas de análisis y conclusiones para pensar los aprendizajes y desafíos que las políticas culturales tienen en un contexto de crisis.

\section{Diagnósticos e historia del estallido social de octubre de 2019}

El origen del estallido social de octubre de 2019 en Chile tiene, al menos, medio siglo de historia. No es posible comprender las raíces de la historia presente del país sin considerar la emergencia de la Unidad 
Popular en 1970 bajo el liderazgo de Salvador Allende (Collier y Sater, 2004). Desde su llegada al poder, y conforme los principios de la "vía chilena al socialismo", se desencadenaron procesos políticos, sociales, económicos y culturales que tuvieron consecuencias estructurales e inéditas para la sociedad chilena. Durante los tres años de gobierno de Allende se construyó un proyecto revolucionario que definió un nuevo horizonte de expectativas para los segmentos sociales pobres e históricamente excluidos, pero que chocaba de manera directa con los intereses y modelos de sociedad de las clases productivas y oligarcas del país (Haslam, 2005; Qureshi, 2009).

Con el derrocamiento de Allende en septiembre de 1973 (Guardiola-Rivera, 2013) y la posterior instauración de la dictadura militar de Augusto Pinochet, el proyecto revolucionario de la Unidad Popular se vio por completo desechado y reemplazado por un nuevo modelo societario inédito en la historia moderna: la economía neoliberal (Taylor, 2006). Bajo los principios de Milton Friedman -y sus seguidores locales, los denominados Chicago boys-, la economía chilena definió un contrato social basado en los principios de la libre competencia y el mínimo rol del Estado. Este modelo económico logró una institucionalidad política con la nueva Constitución de 1980 (Barros, 2002). Validada en un plebiscito caracterizado por irregularidades jurídicas y nula participación de la oposición, en ella no sólo se establecieron los principios y bases legales para sostener un Estado subsidiario y reducido frente al mercado, sino también un resguardo estructural del régimen militar: la presencia de Pinochet como líder del ejército si se lograba la democracia, la presencia de senadores designados por el régimen y el sistema de elecciones parlamentario binominal, entre otros. En su conjunto, la ciencia política denominó estas herencias constitucionales como enclaves autoritarios (Garretón, 2003).

Con el plebiscito de 1989 -y la caída del régimen dictatorial un año después-, Chile vivió la materialización de una política de los acuerdos entre el mando militar saliente y el cuerpo civil entrante (Garretón, 1996; Jocelyn-Holt, 2001). La Concertación de Partidos por la Democracia -coalición gobernante ininterrumpidamente hasta 2009- tuvo que convivir con esta condición paradójica: reconstruir un proyecto democrático con base en principios redistributivos y de justicia social (enfocados en memoria y derechos humanos), pero arrastrando y prolongando las bases económicas y políticas fundamentales del régimen militar. A partir de una democracia protegida no sólo se buscó priorizar una estabilidad política y económica sustentada en principios neoliberales y autoritarios, sino también obstaculizar por la vía legal cualquier mecanismo de cambio o reformulación profunda de ese modelo social (Uggla, 2005). Sin embargo, con la caída simbólica de Pinochet en 2006 y el surgimiento de nuevas demandas sociales y políticas, Chile se preparaba para un nuevo capítulo en su historia (Collins, Hite y Joignant, 2013).

Entre la década de 2000 y 2010 el modelo económico de libre mercado logró una fuerza inusitada en el país. Durante esos años Chile vivió un "milagro" económico que se vio reforzado y legitimado políticamente por reformas constitucionales y sociales (Sehnbruch y Siavelis, 2014). Esta "tesis exitosa" revelaba que la integración social se lograría mediante la ampliación del consumo de la población. En otros términos, que, a través del crédito y el aumento de los niveles de ingreso y educación, sería posible establecer en las / os chilenos un principio de autorresponsabilidad y autocuidado financiero. Como han mostrado algunos autores (Larraín, 2001; Moulian, 1997), la sociedad chilena se autodescribió como formada por consumidores libres, competitivos y autónomos. No obstante, este triunfo individual se develaría como una apariencia.

El plan de los gobiernos democráticos era implantar un neoliberalismo con rostro humano, a pesar de las evidentes desigualdades y exclusiones sociales que el modelo estaba generando (Taylor, 2006; Solimano, 2012). Como han señalado variados estudios y revisiones históricas (PNUD, 2020), Chile se inscribió en el ámbito mundial como una economía ascendente -en 2010 Chile se convirtió en el primer país latinoamericano en ingresar a la Organización para la Cooperación y el Desarrollo Económicos, OCDE-, pero con uno de los índices de desigualdad social más alto y mala distribución de ingresos. Pese a las políticas de superación de la pobreza surgidas desde 1990, las clases pobres y medias tuvieron que desarrollar estrategias de sobrevivencia bajo un modelo económico excluyente e inequitativo (Han, 2012; Araujo, 2009), lo que fue acumulando una sensación de desprotección y frustración. En efecto, los logros económicos alcanzados y la estabilidad política de estas décadas no fueron suficientes para detener el malestar social que emergió desde mediados de la década de 2000. Esta tesis del malestar ha sido expuesta con mayor claridad por las/os investigadores de la sede chilena del Programa de las Naciones Unidas para el Desarrollo (PNUD, 2020). Ya en los primeros informes de desarrollo humano se ponía de manifiesto la paradoja de la modernización en el país: por un lado, un país en creciente complejización capitalista y, por otro, una sociedad que no logra constituirse como plenamente en desarrollo. Después, los enfoques se concentraron 
en explicar los desafíos de los individuos para mejorar su vida diaria y apropiarse / definir su propia trayectoria biográfica (PNUD, 2002). Estas conclusiones, sobre todo culturales, revelaron la dificultad de las/os chilenos para construir sus proyectos biográficos en una sociedad cada vez más individualizada.

Entre las primeras manifestaciones de la crisis del "modelo chileno" estuvieron los movimientos estudiantiles de 2006 y 2011 (Donoso, 2013; Bellei y Cabalin, 2013 y Cabalin, 2012). Enfocados en la gratuidad y calidad de la educación pública, estas movilizaciones llegaron a ser nombradas como el Chilean winter (Villalobos-Ruminott, 2012) y significaron una señal clara del descontento estructural de la población sobre el modelo económico neoliberal. Estos tiempos de la politización en Chile (PNUD, 2015) demarcaron un nuevo trazado social. Al finalizar la presente década, otros movimientos sociales se sumaron al estudiantil, unos antiguos otros emergentes: luchas mapuche (surgidas en la década de 1990), rebelión feminista, nuevas formas de reconocimiento y disidencia sexual, movimientos ecologistas, etcétera. En todos ellos se reconoce como denominador común la lucha por desestabilizar las estructuras de poder hegemónicas heredadas de la dictadura militar. Pero, al mismo tiempo, promueven la emergencia de nuevas formas de participación política y ciudadana inéditas para un país como Chile. El estallido social de octubre de 2019 es la culminación -o inicio- de este proceso histórico de casi medio siglo. Una crisis de legitimación de un modelo impuesto en dictadura y fortalecido durante 30 años en democracia.

Varios han sido los diagnósticos que han expuesto esta crisis y malestar social (Mayol, 2012; Ruiz, 2015; Garretón, 2016; Araujo, 2016; PNUD, 2020; Somma et al., 2020). Empero, desde el estallido de octubre de 2019, ha habido consenso en que uno de los motivos principales ha sido la desigualdad estructural de la sociedad chilena y la acumulación de abusos y alzas en los servicios básicos (salud, educación, agua, luz, transporte, medicamentos) (Garcés, 2020 y 2019). De igual forma, el estallido no se explica sin las actuales luchas feministas (Zerán, 2019) y los variados movimientos sociales históricos (estudiantiles, ecológicos, sexuales, por previsión social digna, entre otros). Todo esto ha llevado a cuestionar las estructuras

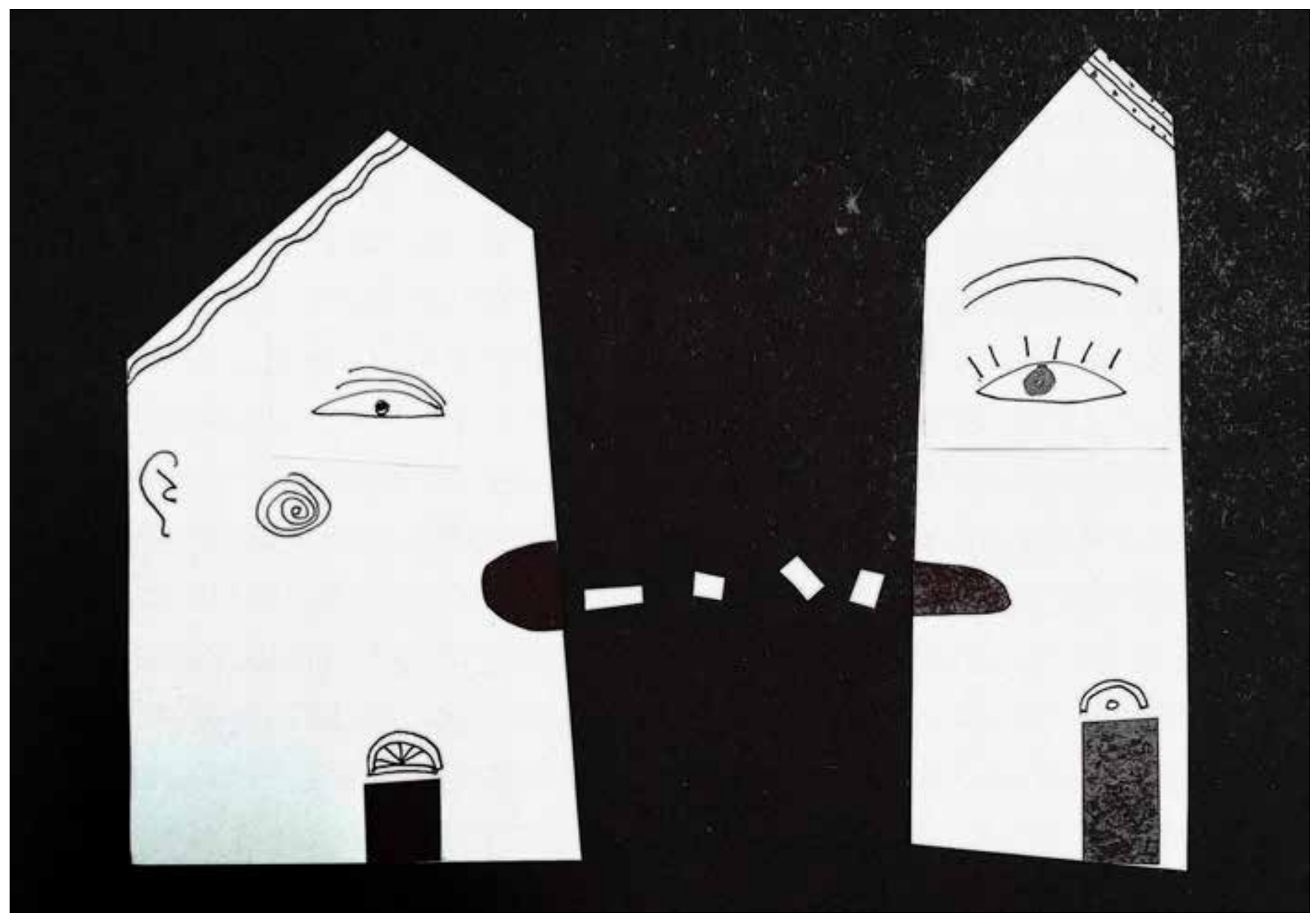


institucionales que permitieron la ampliación de la desigualdad y los abusos: la Constitución política de 1980. Esta carta magna "tramposa" (Atria, 2017) ha sido destacada como el eje del problema político y económico del Chile actual, y los actores políticos con representación parlamentaria decidieron llamar a un plebiscito para derogar esa Constitución y generar una nueva mediante una convención constituyente.

El estallido social ha posibilitado una reactivación democrática (Garcés, 2020) y un escenario deliberativo inédito en espacios culturales, centros comunitarios y plazas públicas: pero también ha generado un paisaje urbano caracterizado por actos de violencia, violación a derechos humanos por parte del Estado y un centenar de marchas y manifestaciones urbanas que han cambiado el diario vivir de una zona: la Plaza Italia o Plaza Dignidad. Entendidos como esferas deliberativas por excelencia, los espacios culturales, museos, cines, bibliotecas y teatros se vieron expuestos a estos actos y sus consecuencias territoriales, políticas y culturales. En otros términos, por la revuelta, se vieron interpelados e interrogados a actuar y discutir su misión.

\section{Museos y espacios culturales como esferas públicas deliberativas}

Luego de los procesos revolucionarios en Europa en el siglo xix, los museos -y espacios culturales en general, tales como salas de concierto, teatro, danza y bibliotecas- han desempeñado un papel clave en la reflexividad política y cultural de las sociedades modernas. Estos lugares, herederos de colecciones monárquicas, religiosas y burguesas, sirvieron como depósitos de conocimientos, objetos patrimoniales, relatos históricos, representaciones visuales y, sobre todo, discursos de poder. La historia de la cultura ha demostrado cómo estos espacios, pensados en un principio como zonas de distinción y exclusión social y, posteriormente, como lugares de esparcimiento y civilización, sirvieron como plataformas de regulación social.

Tony Bennett (1995) ha expuesto con claridad cómo la formación de los museos no puede comprenderse de modo adecuado sin incluirlos en un proceso cultural más complejo de gubernamentalidad: es decir, como un espacio útil para el ejercicio de nuevas formas de poder. Siguiendo los postulados teóricos de Michel Foucault, Bennett precisa que los museos, además de ser pensados como lugares útiles para la vida urbana, servían para la salud mental y moral de los ciudadanos. Considerados tan importantes como la distribución de agua, las luces callejeras y las veredas, estos espacios denominados culturales fueron asignados bajo el propósito de civilizar a la población como un todo. En su investigación, Bennett describe cómo estas esferas, en sus inicios, eran útiles como escenarios de diferenciación entre las elites de cada país, pero que, con el pasar los años, esa disposición pública de alta cultura servía para transformar los modos de vida privados y públicos de los ciudadanos. En este sentido, tanto los museos como las bibliotecas tenían los mismos propósitos que una plaza o parque en la ciudad: al caminar por ellos no sólo se lograba contemplar la naturaleza ordenada, sino también se paseaba por los senderos donde la civilización había dominado la naturaleza salvaje (lo bárbaro). Los museos servían entonces para el gobierno de sí. Con su disposición en la ciudad podía controlarse el alcoholismo, fomentar la ética del trabajo individual así como reducir los riesgos de nuevas revueltas sociales.

Durante los siglos XVIII y xIx, el Estado soberano comprendió los espacios culturales como instancias disciplinarias. Bennett aclara que la organización y disposición de los cuadros, esculturas y libros fue pensada para enseñar con mayor facilidad el patrimonio de cada nación: al establecer los tiempos de observación, obras destacadas y secciones especiales, los Estados inscribían el modo de enseñanza "correcto" de la historia de cada pueblo. De esta forma, los museos fueron entendidos en cuanto espacios culturales deliberativos. Al ser descritos como lugares de representación y despliegue de discursos, Bennett advierte que estos espacios sirvieron como plataformas de apoyo para la naciente esfera pública burguesa.

Apoyándose en la teoría de la esfera pública de Jürgen Habermas, Bennett apunta que los museos surgieron y crecieron a la par de los debates sociales y político-críticos del siglo xIx. Las galerías de arte, museos, salones de música, teatros y cafés florecieron con la crítica cultural y artística de la vida urbana parisina, berlinesa y londinense. Al mismo tiempo, y gracias a la mercantilización de los productos culturales -prensa, fotografía, literatura de bajo costo, etcétera-, la esfera pública comenzó a ganar un terreno político inédito. En su conjunto, y con la deselitización de los espacios culturales, se logró una separación-liberación de la tradición cultural hegemónica y se constituyó una esfera pública moderna. Sin embargo, y a pesar del progresivo ingreso de las mujeres y las diversas clases sociales a museos, bibliotecas, teatros y salones en las décadas siguientes, estos espacios mantuvieron un rol pedagógico y formativo, antes que transformador y social. Ese rol apenas llegaría a cumplirse en la segunda mitad del siglo xx.

En Culture and the Public Sphere, Jim McGuigan (1996) explora con profundidad este problema. En él 
puntualiza que desde la década de 1960 las políticas culturales se conectan con la esfera pública en su sentido más general: en los choques de ideas, luchas institucionales y relaciones de poder en la producción y circulación de significados-bienes simbólicos. Desde su surgimiento como acciones gubernamentales, las políticas culturales son parte del debate político y no materia de administración técnica. En cuanto tales, advierte McGuigan, deben ser tratadas en relación con las determinaciones económicas y políticas de cada sociedad y época. Ellas son parte de la discusión crítica y racional de la esfera pública. Si bien esta última es fragmentada, múltiple y diversa, es en los espacios culturales donde pueden generarse instancias para que todos tengan la posibilidad de participar de forma equitativa en ella. Y es justamente en este punto donde McGuigan se enfoca. Siguiendo los postulados de Michel Foucault, Jürgen Habermas y Raymond Williams, en su libro refuerza la idea de que las instituciones culturales producen y circulan significados y prácticas simbólicas como ninguna otra esfera. En la segunda mitad del siglo xx, estos espacios no pueden pensarse sólo como escenarios de control, restricción y regulación social, sino como generadores de controversias públicas.

McGuigan afirma que en las sociedades democráticas las políticas culturales deben ser entendidas como reflejo de la voluntad pública, es decir, como instancias que influyen en las instituciones culturales para lograr cambios sociales. Es en los museos, bibliotecas, teatros, salas de concierto, galerías, etcétera, donde deben reducirse las diferencias e inequidades de poder. Esos espacios, entendidos como públicos y "abiertos para todos", deben funcionar entonces como escenarios donde la razón y los acuerdos comunicativos operen en igualdad de condiciones.

Al profundizar en estos debates, Tony Bennett (2005) ha señalado que, a finales del siglo xx y comienzos del $\mathrm{xxI}$, los museos e instituciones culturales pueden ser comprendidos como laboratorios cívicos. En efecto, luego de los ecomuseos y las nuevas tendencias en museología surgidas desde la década de 1970, los museos funcionaron como instrumentos para la promoción de la diversidad cultural y esto generó una nueva forma de ser pensados. Con base en la metáfora de los laboratorios de ciencias, Bennett piensa los museos como espacios donde se manipulan y experimentan subjetividades, objetos culturales y regulaciones sociales. En su conjunto, y como lo hicieron en los siglos pasados, pueden promover saberes inéditos y crear nuevos regímenes de verdad.

Si bien Bennett habla de la dificultad de comparar los museos con el funcionamiento real de los labora- torios científicos, destaca que los primeros despliegan los conocimientos experimentados directamente en la sociedad, produciendo nuevas realidades y relaciones imaginables y perceptibles. Así, al ser espacios epistemológicos y públicos -donde se establecen ensamblajes entre personas-públicos, objetos-culturales y espacios expositivos-experimentales-, los museos se constituyen como dispositivos de intervención en lo social. Con los resultados de cada nueva exposición pueden producirse cambios en las formas de ver, percibir y regular tanto una sociedad específica (las identidades locales y territoriales) como las otredades (diversidades culturales).

Jennifer Barrett (2012) y Clive Gray (2015) han seguido esta discusión en años recientes. Por una parte, Barrett afirma que los museos contemporáneos son espacios abiertos, instituciones democráticas para y de la gente. Gracias a la experiencia acumulada en las últimas décadas, los museos y espacios culturales han inscrito en sus misiones y objetivos a sus comunidades y territorios como agentes de interés, pues son tanto productores de cultura como renovadores activos del rol público de ellos. En la actualidad, explica Barrett, los museos han alcanzado un compromiso crítico en el discurso público. Al ser espacios públicos y democráticos, los museos e instituciones culturales han perdido la histórica jerarquía de poder que poseían. Junto con ello, se han descrito como espacios de representación de la diversidad cultural y como generadores de conocimientos compartidos con sus territorios y comunidades. Lo interesante al respecto, especifica Barrett, es que los museos y espacios culturales de hoy en día son comprendidos como escenarios de controversias y debates crítico-culturales. En este sentido, los museos y espacios culturales no son plataformas de apoyo a la esfera pública: son ellos mismos una esfera pública. Como indica Barrett, son esferas públicas culturales de deliberación social y política; están pensados para que las personas tengan la oportunidad de participar en los procesos democráticos generados simbólicamente en sus paredes y pasillos. En su interior no sólo se disponen obras que reflexionan sobre lo social, sino que, al ser exhibidas ahí, producen discursos públicos. Si los museos no fueran accesibles para todos, entonces sería evidencia de una falta de cohesión social, o, en otras palabras, la democracia en sí estaría en riesgo.

Por su parte, en The politics of museums Gray se enfoca en entender los museos como agentes políticos. Ellos están involucrados tanto en su relación con el mundo globalizado como con los conflictos poscoloniales; tanto en las decisiones internas de poder entre los profesionales como en las formas de pensar e influir en 
la concepción de museo en general. Lo llamativo de la aproximación de Gray es su interés por comprender el papel que cumplen los individuos concretos en la gestión de los museos (directores, curadores, conservadores, encargados de educación y mediación, profesionales, técnicos), además de las influencias y presiones externas (públicos, agentes estatales o ministeriales, vecinos, comunidades y territorios, no-públicos). En su conjunto, Gray señala que lo político de los museos no sólo se da en su capacidad de ejercer poder, legitimidad cultural, preferencias hegemónicas o fomentar ideologías específicas en la sociedad, sino también en las decisiones, racionalidades, influencias y prácticas políticas que se crean en el interior de ellos y entre ellos. En este sentido, el ejercicio de poder en los museos y espacios culturales es una experiencia sistémica: genera acciones políticas para el entorno (la sociedad), pero el entorno asimismo produce presiones en su interior. Para Gray, los museos son espacios donde se producen acuerdos y desacuerdos entre los agentes intervinientes (directores, profesionales, vecinos, públicos, políticos, evaluadores, etcétera) y los resultados de esas negociaciones pueden ser insospechados y con consecuencias involuntarias. Al pensar el rol de los museos y espacios culturales hay que tener en cuenta tanto el equipo interno de esos espacios como los públicos potenciales o los grupos excluidos de la sociedad (y todos los agentes que están en medio de ambos).

En definitiva, y a pesar de que los espacios culturales y museos tienen relativamente poco impacto en la "gran política", su misión es ser esferas que fomenten, cuestionen y refuercen los imaginarios -históricos y en curso- de las sociedades. Y este aspecto ha sido fundamental para comprender su situación en América Latina (Castilla, 2010; Pinochet, 2016).

¿Cómo responder a esa misión en un estado de excepción? Si la significancia política de los museos y espacios culturales es servir como esferas públicas culturales deliberativas, ¿cómo actuar frente al desarrollo de marchas, protestas y acontecimientos de una revuelta social en sus territorios? En definitiva, en un contexto de rupturas y cuestionamiento a la sociedad chilena, ¿qué medidas, acciones y respuestas dieron los museos y espacios culturales cercanos a la Plaza Italia-Dignidad luego del 18 de octubre de 2019 ?

\section{Metodología}

Para dar respuestas a las preguntas aquí planteadas se identificaron los principales espacios culturales (museos, bibliotecas, teatros, cines, etcétera) geográficamente cercanos a la denominada zona cero del estallido (Plaza Italia-Dignidad). Esta zona comprende un área de diez kilómetros cuadrados y se ubica, sobre todo, en el centro de la ciudad; la avenida Libertador Bernardo O’Higgins -entre el Palacio de La Moneda por el oeste y Salvador por el este-fue el eje principal de las protestas entre el 18 de octubre de 2019 y enero de 2020, pero la zona puede ampliarse por el lado norte hasta avenida Costanera Norte y el lado sur hasta Francisco Bilbao-Curicó. Sin duda, esta delimitación es arbitraria y no se condice con los territorios propios de la revuelta (ésta se desarrolló en variadas zonas de la ciudad y del país, pero es en esta área de la capital donde se produjeron los mayores enfrentamientos entre manifestantes y fuerzas policiales). Dentro de esa delimitación geográfica se identificaron 19 espacios culturales, ${ }^{1} 13$ de los cuales se tomaron en cuenta como muestra y donde se entrevistó a trabajadores y representantes o directivos entre marzo y abril de 2020. Las entrevistas fueron semiestructuradas, duraron aproximadamente 30 minutos y se enfocaron en las seis dimensiones de análisis ya mencionadas. Con el fin de mantener el anonimato de los entrevistados, no se indican ni nombran los espacios culturales. Además del análisis cualitativo de las entrevistas, se revisaron reportajes de prensa, memorias y documentos oficiales de los espacios.

\section{Espacios culturales en la zona cero: respuestas, acciones y vínculos bajo el estallido}

Los museos y espacios culturales situados alrededor de la zona cero poseen características organizacionales e institucionales particulares (dependencias públicas, privadas e independientes), distintos niveles de complejidad según su tamaño, y su misión depende de su área artística específica de trabajo (véase anexo 1). Históricamente, los museos y espacios culturales han desempeñado un papel decisivo en el proceso de

1 Centro Cultural Palacio de La Moneda, Galería весн, Teatro del Puente, Centro Cultural Gabriela Mistral, Museo de Arte Contemporáneo sede Parque Forestal, Museo Nacional de Bellas Artes, Museo de Guímica y Farmacia, Centro Cultural de España, Museo Violeta Parra, Museo Benjamín Vicuña Mackenna, Cine Arte Alameda, Museo de Artes Visuales, Cine El Biógrafo, Biblioteca de Providencia -sedes Parque Bustamante y Parque Balmaceda-, Cine Arte Normandie, Museo de Arte Colonial, Teatro de la Universidad de Chile, Galería Gabriela Mistral y Biblioteca Nacional. 
democratización cultural en Chile (Subercaseaux, 2011 ). Si durante el inicio de la república, en los siglos xIx y xx, cumplieron un rol clave para la construcción de la identidad nacional (Urizar, 2012; Alegría, 2019), a finales del siglo pasado enfrentaron un proceso de reconfiguración estructural con base en la nueva institucionalización cultural en el contexto posdictatorial. Este devenir de los museos y espacios culturales por constituirse en espacios abiertos y vinculados con sus comunidades y públicos se ha acrecentado durante los últimos años (Subdirección Nacional de Museos, 2015) debido, en parte, a los desafíos generados por la reducción de sus públicos y la necesidad de evaluar sus gestiones (Ministerio de las Culturas, las Artes y el Patrimonio de Chile, 2019; Observatorio de Políticas Culturales, 2019).

En este escenario, los museos y espacios culturales en Chile han debido sobrevivir mediante aportes públicos y acciones concretas para revertir el distanciamiento de sus visitantes, y durante el "estallido social" se ponían a prueba los postulados discursivos de apertura y lógica democrática. Si bien las experiencias, decisiones $\mathrm{y}$ acciones tomadas por cada espacio durante el estallido fueron disímiles entre sí, existen elementos compartidos que permiten dilucidar tendencias comunes. A partir de las dimensiones de análisis definidas para esta investigación, fue posible establecer líneas interpretativas que contribuyen a la comprensión del fenómeno y dan respuestas a las preguntas formuladas en este estudio. Dicha sistematización ofrece una cartografía analítica aún en construcción.

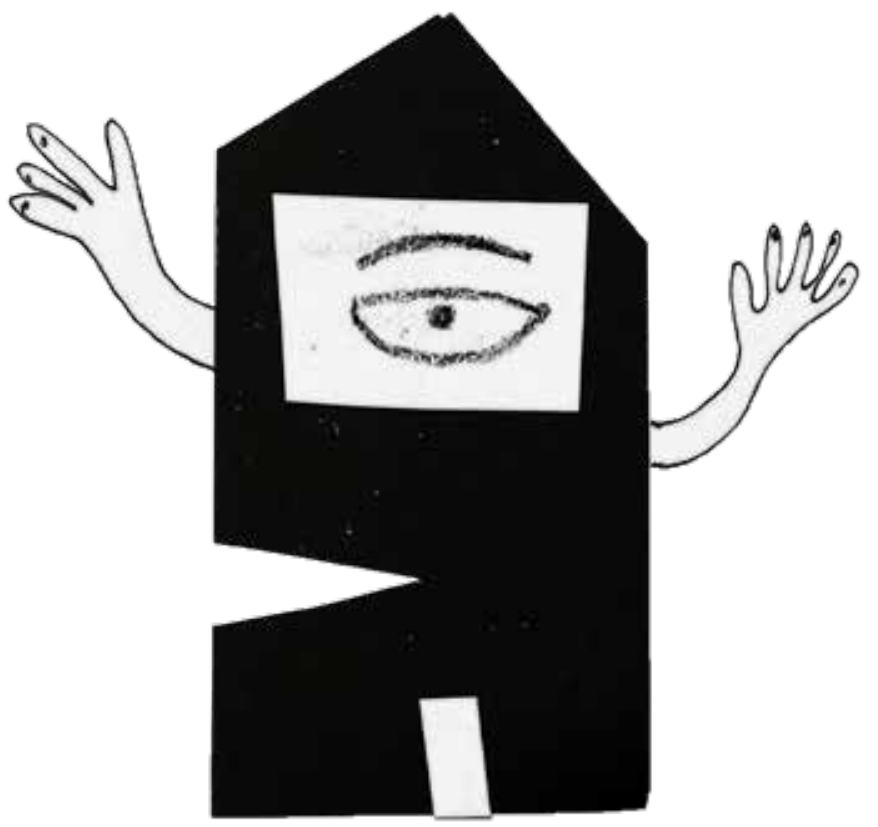

Acciones inmediatas-contingentes al inicio del estallido

La semana del 14 de octubre se produjeron diversas acciones de evasión del pago en el transporte público. Durante esos días, las fuerzas policiales fueron desplegadas a lo largo de las estaciones de la red de metro con el fin de evitar estas acciones realizadas, principalmente, por estudiantes secundarios. El viernes 18 culminaba una semana caracterizada por el aumento progresivo de las evasiones masivas -tanto de estudiantes como de ciudadanos comunes- y el llamado a huelga de gremios de trabajadores por el alza del valor de los pasajes del transporte público. Con el objetivo de desincentivar la evasión, ese día el gobierno redujo de manera sustantiva la frecuencia de buses y metros, lo que generó una crisis de movilidad de las personas por la ciudad. Debido a este escenario crítico, en la principal vía de la capital -la "Alameda" Libertador Bernardo O’Higgins-, empezó a reunirse un número creciente de personas en dirección a Plaza Italia para protestar por la situación. A partir de esa tarde comenzó el estallido social de octubre.

Los museos y espacios culturales cercanos a la zona cero estaban en medio de diversas actividades y programaciones. En Chile, la primera quincena de octubre se distingue por el retorno de vacaciones de las fiestas patrias y por la mejora del clima (inicio de la primavera). Durante el jueves y el viernes de esa semana, la mitad de los espacios habían programado inauguraciones de exposiciones o inicios de ciclos de programaciones. Todos los espacios culturales y museos estaban abiertos y atentos a los problemas de transporte en la capital, así que habían tomado providencias con sus trabajadores y públicos. Aquellos que no tenían programada alguna actividad esa tarde cerraron sus puertas con anticipación a fin de facilitar el desplazamiento de sus trabajadores a sus hogares.

Desde las 18 horas, la concentración de personas en la zona cero creció de manera exponencialy, de acuerdo con las / os entrevistados, en los equipos se generó un monitoreo permanente de la situación. Esto tenía como objetivo ir evaluando en línea los acontecimientos "de la calle" para tomar decisiones sobre cerrar los espacios o mantener la programación definida. Sin embargo, en las horas siguientes, se iniciaron los primeros enfrentamientos entre la fuerza pública y los manifestantes, lo que desencadenó una reacción masiva de los espacios por cerrar sus puertas, evacuar a sus públicos y asegurar las condiciones de sus trabajadores. Según las / os entrevistados, el nivel de violencia era inusitado de acuerdo con sus experiencias previas: además de las tradicionales piedras y destrozos de bienes públicos, 
se incendiaron edificios aledaños, se hicieron barricadas en las calles y se desató una fuerte represión policial. Esto llevó a los espacios y museos a cerrar por completo $\mathrm{y}$, los que poseían equipos de guardias, a reforzar su presencia. Junto con ello, y según se señaló en las conversaciones, entre los equipos se produjo una sensación de "perplejidad", "incertidumbre", "temor" y "desorientación", pero, al mismo tiempo, un "entusiasmo", "emoción” y “optimismo" por los acontecimientos en curso. Las primeras impresiones de esas horas eran que esto duraría "la noche" y se volvería a la "normalidad" en unas cuantas horas.

El 19 de octubre, y al evaluar el escenario político y de movilización de la ciudad, la totalidad de los museos y espacios culturales cerraron durante ese fin de semana. Como indicaron las conversaciones, el monitoreo de los acontecimientos era permanente y las decisiones fueron claras: mantener cerrados hasta que el territorio permitiera la llegada segura de los trabajadores, y no hubiera riesgo de amenazas físicas para ellos ni para los edificios (en especial por incendios). En el transcurso de los días posteriores, los espacios dependientes de organismos públicos recibieron tanto directrices de autoridades ministeriales y estatales de mantener cerrados como ayuda para reforzar medidas de seguridad de la infraestructura y de guardias -con acceso sólo a trabajadores-, mientras que los espacios privados e independientes abrieron de manera parcial, debido, en parte, a las exigencias de seguridad de su edificación y equipo. En el primer caso, a las afueras de los espacios y museos de dependencia pública se realizaron intervenciones por parte de los trabajadores (como colgar lienzos para unirse a la protesta o presentaciones artísticas que respaldaban las movilizaciones). En el segundo caso, fueron los mismos equipos de trabajo los que se mantuvieron en su interior con el fin de proteger, cuidar y resguardar las instalaciones. Varios de estos espacios independientes, al estar en zonas estratégicas, sirvieron como puntos de resguardo de los manifestantes y de primeros auxilios, lo que generó un vínculo de cuidado mutuo entre ellos y el espacio cultural.

Durante las semanas sucesivas los museos y espacios culturales debieron suspender y/o reprogramar su calendario de actividades. Debido a los acontecimientos que se estaban desarrollando -en especial de enfrentamientos con alto nivel de violencia, saqueos e incendios en edificios aledaños, como farmacias, bancos y oficinas públicas- algunos museos públicos decidieron proteger sus obras en depósitos especiales o trasladaron objetos valiosos patrimoniales hacia áreas sin riesgo. Otros espacios culturales privados abrieron sus puertas "cuando se podía" y repusieron sus actividades (si surgían problemas en el exterior, debían evacuar a su público por vías seguras). Además, se "camuflaban" apagando las luces para aparentar estar cerrados o instalando protecciones poco evidentes. Otros espacios más institucionales, debido a las manifestaciones y acciones que ocurrían a las afueras de sus puertas, optaron por reforzar sus accesos y colocaron muros de fierro (tipo bunkers). En general, las / os entrevistados dijeron que, durante las primeras semanas, se determinó no eliminar ni borrar los rayados realizados en las paredes de los museos y espacios. Existió un reconocimiento amplio de que servían como soportes de expresiones del movimiento: por tal razón, se registraron (fotografiaron), archivaron y sistematizaron como "documentos históricos".

Los espacios culturales privados e independientes, al mantener cierta apertura, lograron seguir con exposiciones o presentaciones artísticas, pero éstas sufrieron cambios en sus horarios, títulos y formatos. Sin embargo, todos los espacios y museos analizados precisaron -o es posible leer en sus memorias del añoque la asistencia de públicos se redujo a niveles críticos e inexistentes en su historia. Salvo algunos casos -donde se llevó a cabo una inauguración de exposición-, el resto de los espacios casi no recibió públicos durante los meses de octubre, noviembre y diciembre.

\section{Vínculos de apoyo}

\section{y protección institucional-pública al espacio}

Durante el estallido social, los museos y espacios culturales no sólo debieron sortear el cambio radical de sus programaciones y establecer nuevos protocolos de funcionamiento y seguridad, también enfrentaron exigencias organizacionales y crisis de financiamiento-operación. Al consultarles a las/os entrevistados sobre los niveles de apoyo o protección de las instituciones culturales públicas, es decir, del Ministerio de las Culturas, las Artes y el Patrimonio de Chile, las respuestas varían significativamente según el tipo de espacio. Los museos y espacios culturales de dependencia pública recibieron, desde los primeros días del estallido, apoyo económico y protección mediante el reforzamiento de guardias privados. En la mayoría de estos casos, la comunicación fue directa con los agentes ministeriales. No obstante, en los espacios culturales de dependencia universitaria, el vínculo con la institucionalidad pública cultural fue más débil. Algo parecido se observó en los espacios independientes y privados: según las/os entrevistados, casi no hubo vínculos de cooperación y trabajo con el ministerio -ni 
en reuniones ni en comunicaciones- y la situación dependió de la administración de contactos de cada equipo.

Otros nexos identificados por las / os entrevistados fueron con carabineros (policía) y autoridades municipales, pero se trató de colaboraciones esporádicas y en situaciones concretas, aunque en general estas conexiones fueron percibidas más bien como problemáticas: es más, muchas veces se comprendieron como agentes en directa contradicción o rechazo con la misión del espacio.

Uno de los vínculos reconocidos por las/os entrevistados se generó entre los mismos museos y espacios culturales. Entre los más claros al respecto están una experiencia previa denominada "Barrio Arte"-que reunía a un grupo específico de espacios- y "Barrio en Diálogo" que, durante el estallido, logró ampliar su campo de acción con otros espacios culturales, la comunidad y otras organizaciones territoriales (como cafés, restaurantes, negocios) en vistas a discutir los acontecimientos acaecidos durante el estallido. Este tipo de espacios de colaboración entre los museos y espacios culturales fue percibido por las / os entrevistados como una instancia que redujo la incertidumbre y permitió establecer líneas de trabajo colaborativa y de protección mutua durante esos meses.

\section{Relaciones laborales internas y cambios organizacionales}

Según las entrevistas, durante el estallido social los museos y espacios culturales tanto públicos como privados e independientes no realizaron cambios sustantivos en los equipos de trabajo. Por el contrario, al margen del tipo de espacio y museo, se evidenció una preocupación constante por resguardar la integridad física de los trabajadores durante sus horas laborales, así como también por su salud mental (de "contención”, “cuidado emocional”, “carga negativa”). Al mismo tiempo, según las / os entrevistados, los equipos y trabajadores de los espacios y museos fueron determinantes durante el estallido, ya que apoyaron la misión histórica de ellos además de las necesidades emergentes que surgían cada día por causa de las movilizaciones (se redistribuyeron las funciones). Con todo, al finalizar 2019, algunos espacios culturales independientes debieron prescindir de algunos servicios profesionales y los museos de dependencia pública eliminaron a profesionales por honorarios externos. Sólo los equipos permanentes mantuvieron sus cargos.

Uno de los puntos clave de discusión entre las/os entrevistados fue el surgimiento de ciertas tensiones entre los trabajadores de museos y espacios culturales de dependencia pública y sus equipos directivos, respecto de la forma de tematizar o actuar durante el estallido social. En otras palabras, emergió una discusión interna entre los trabajadores -que sentían afinidad por el movimiento y veían la necesidad de participar como agentes culturales desde el espacio cultural o museo público-y los directivos -quienes recibían directrices desde agentes públicos gubernamentales jerárquicos de no actuar ni involucrarse en la movilización. Según algunas /os entrevistadas/os, los trabajadores organizaron encuentros, reuniones y reflexiones sobre el papel de los museos y los espacios culturales de dependencia pública en el contexto del estallido -así como por sus propias condiciones laborales precarias-, pero no fueron promovidas ni reforzadas por los directivos. Para estos últimos, apoyar el movimiento iba en contra de sí mismos, pues eran parte de "lo criticado". En este sentido, salieron a la luz tensiones en las "estrategias del tratamiento" del conflicto social entre trabajadores y directivos. Por su parte, en los espacios culturales independientes o privados la situación fue distinta, aunque se dieron debates internos sobre "la forma" de expresar el respaldo. No obstante, en las entrevistas se evidenció un trabajo en bloque de apoyo tanto a la movilización como a la labor realizada en el interior de los espacios. En este sentido, el trabajo de compromiso estaba fortalecido por todos los estamentos, aunque esto ocurrió sobre todo en espacios culturales independientes.

\section{Vínculos entre manifestantes, públicos y comunidad del espacio durante el estallido (comunidades contingentes)}

Una de las dimensiones centrales de los museos y espacios culturales es su relación con el territorio donde se sitúa. Desde el 18 de octubre, en el contexto del estallido, el territorio de esos espacios se convirtió en una zona de enfrentamientos entre manifestantes y fuerzas públicas, y esto tuvo consecuencias para los museos y espacios culturales. ${ }^{2}$ Los manifestantes, considerados comunidades contingentes, utilizaron

2 El viernes 27 de diciembre de 2019 uno de los espacios culturales independientes, el Centro Arte Alameda, sufrió un incendio -por razones que se investigan- que destruyó gran parte de su infraestructura. Dos meses después, el viernes 28 
ese espacio público como un territorio resignificado: la zona cero se transformó en Plaza Dignidad y día tras día se apropiaron, en diversas formas, de ese espacio, siendo los viernes el día de mayor afluencia y conflicto barrial.

Las entrevistas permitieron advertir, principalmente, tres tipos de relación de los museos y espacios culturales en sus territorios: a) con los manifestantes, b) con los públicos tradicionales y c) con las comunidades circundantes (vecinos). Los museos y espacios culturales de dependencia pública mantuvieron una relación "distante" con los tres tipos identificados, en especial con los manifestantes (en particular por el temor a saqueos, protección a los edificios patrimoniales, robos de documentos, etcétera). Si bien en ocasiones se pusieron a disposición salas de reuniones para encuentros con los vecinos y comunidades, las / os entrevistados de algunos museos de dependencia pública y tamaño pequeño reconocieron que fueron instancias de rendimiento contextual, es decir, no siempre se lograba una asistencia importante y dependía de muchas variables (seguridad, horario, día, calidad del aire, etcétera). Los ejemplos exitosos de encuentros con vecinos y comunidades se realizaron en especial afuera de las entradas principales de los espacios culturales y museos (por ejemplo, "Coloquio de perros"). Los mayores encuentros, cabildos y reuniones masivas de artistas, gestoras/es culturales, investigadoras/es, comunidades vinculadas al mundo artístico y públicos tuvieron lugar en espacios culturales independientes alejados de la zona cero. En el caso de museos de mayor tamaño, y aun cuando mantenían fuertes lazos históricos con sus comunidades y vecinos, debieron suspender sus trabajos territoriales y enfocarse en situaciones contingentes, donde los vínculos se restringieron a solicitudes específicas (por ejemplo, mayor seguridad durante la noche por miedo a incendios o peticiones de modificación de inmobiliario público perteneciente a los museos). De la misma forma, a veces, y según dicen las/os entrevistados, los museos de dependencia pública y algunos espacios culturales recibieron amenazas de ataques y robos.

A diferencia de los museos y espacios culturales públicos, los espacios independientes sostuvieron una política de apertura y apoyo a los manifestantes y, "en la medida de lo posible", mantuvieron su programación. Además de servir como refugio para personas huyendo de diversas formas de represión -bombas la- crimógenas, lanzaaguas, represión directa de fuerzas policiales-, también fueron espacios de atención médica a heridos durante las protestas. En cuatro casos, dentro de estos espacios se implementaron piquetes de salud de la Cruz Roja o de estudiantes-profesionales de la salud, lo que significó un involucramiento directo con el territorio y la contingencia del estallido. Al disponer de dispositivos de salud y resguardo, las / os entrevistados narraron que los manifestantes se sintieron amparados y protegidos. De hecho, estos espacios culturales y museos programaron actividades artísticas vinculadas a la protesta social y efectuaron conversatorios con los públicos y artistas luego de funciones y exposiciones. A pesar del riesgo de esta situación, en las entrevistas se comentó la percepción de que el vínculo y el reconocimiento del territorio, los públicos y las comunidades sobre estos espacios se vio fortalecido y ampliado.

\section{Uso y estrategia comunicacional del espacio cultural}

Las redes sociales y las estrategias comunicacionales fueron una dimensión emergente durante el estallido, la cual fue reconocida como clave por parte de todas / os las / os entrevistadas/os. Desde el 18 de octubre, y a causa de los cierres y cambios de programación por parte de los museos y espacios culturales, la vía de comunicación con sus comunidades, públicos y sociedad en general fue a través de las redes sociales (Facebook, Twitter, Instagram). Según quedó en evidencia en las entrevistas, en los primeros días estos medios fueron utilizados para informar el cierre o los cambios de horarios de la programación. Sin embargo, a los pocos días, algunos museos y espacios culturales fueron increpados -"funados"- por usuarios tanto por el uso de ciertos términos como por la falta de referencias al estallido social. Por ejemplo, en un caso, la frase "volveremos cuando se regrese a la normalidad" recibió críticas de los usuarios debido a que, luego del estallido, ya nada volvería a la normalidad. Con base en ese tipo de experiencias, las comunicaciones comenzaron a ser más cuidadas y reflexionadas.

Si en un comienzo las comunicaciones se enfocaron en informar los cambios de horarios y programaciones, en el transcurso de las semanas subsecuentes se gestaron diversas estrategias: por una parte, los

de febrero, ocurrió lo mismo con el Museo Violeta Parra, espacio cultural privado, sin fines de lucro. En ambos casos, fue patente cómo la vinculación y tratamiento con sus territorios jugó un rol clave en su función y devenir en cuanto espacios culturales y museos. 
museos y espacios culturales de dependencia pública y universitaria se mantuvieron difundiendo sus horarios de funcionamiento y decisiones contingentes. No obstante, en algunos de ellos, se utilizaron obras de sus colecciones para fomentar y ampliar el debate sobre los acontecimientos sociales. Por otra parte, algunos espacios culturales tomaron una "posición de apoyo" a la movilización social, lo que implicó críticas y respaldos al mismo. Incluso, en uno de ellos, los directivos y equipo profesional recibieron amenazas por parte de grupos contrarios a la movilización. Finalmente, otros espacios culturales independientes, además de notificar sobre sus actividades, solicitaron en sus redes sociales ayuda en materiales de primeros auxilios, alimentos, profesionales de la salud, etcétera. En su conjunto, las / os entrevistados manifestaron que la comunicación a través de las redes sociales sirvió como un termómetro o indicador para la toma de decisiones en los museos y espacios culturales. Pero, de manera simultánea, contribuyeron a que los espacios y museos comenzaran a ser conocidos y reconocidos tanto por los públicos y comunidades históricas como por la sociedad en general.

\section{Imaginarios $y$ perspectivas futuras} de los espacios culturales posestallido

Luego de cinco meses de haber comenzado el estallido, las / os entrevistados señalaron que la incertidumbre y complejidad acumulada hacían difícil establecer una hoja de ruta posible para sus museos y espacios culturales. Empero, fue dable identificar tres grandes relatos. Por una parte, entre los museos y espacios culturales independientes, universitarios y privados surgió un discurso orientado a la necesidad de construir un nuevo trato con los territorios, comunidades y públicos. En varias ocasiones se mencionó, por ejemplo, la "Declaración de Córdoba" de 2017, haciendo referencia al papel social y político de los museos en el contexto del estallido. Las lógicas participativas de la cultura fueron vistas como una exigencia real para el futuro de las políticas culturales: es decir, restablecer las confianzas y afectos entre los territorios y los espacios y museos.

En segundo lugar, y debido a la alta incertidumbre que generó el estallido y a las relaciones inéditas que se suscitaron entre cultura y sociedad, hubo quienes hablaron de la urgencia de establecer políticas culturales que produjeran un fuerte quiebre a los modelos económicos dominantes y propiciaran una democracia cultural efectiva; pero que, sin embargo, alcanzar esa meta no dependía de los espacios culturales y museos, sino de la sociedad en su conjunto. Además, se requería superar el muy extendido imaginario de que la cultura y las artes son un espacio privilegiado para un segmento de la sociedad, y que, en cambio, son un derecho de todos.

Finalmente, fue posible identificar discursos específicos: las / os entrevistados indicaron que la emergencia de las comunicaciones y la digitalización de las colecciones y acciones de los museos y espacios culturales será un escenario futuro real. Asimismo, las entrevistas refuerzan las dudas sobre el rol que los museos y espacios culturales cumplirán como esferas públicas en un escenario de nuevos cierres y suspensión de la programación anual. Sumado a lo anterior, se menciona la inseguridad que han alcanzado los museos y espacios culturales por el financiamiento futuro y la necesidad de reconstruir tanto la infraestructura dañada de algunos de ellos, como la urbanidad misma de la zona cero.

\section{Conclusiones: apuntes para pensar las políticas culturales en contextos de crisis}

A partir del 18 de octubre la sociedad chilena ha vivido un concatenamiento de sensaciones contradictorias y el surgimiento de imaginarios inéditos de sociedad. El estallido social significó una demostración explícita de malestares históricos de gran parte de la población. Además de poner en crisis los esquemas tradicionales de la sociedad, introdujo en el continuum de la historia la exigencia de pensar una sociedad otra basada en principios de equidad, dignidad y justicia. Pese a ello, esto ha tenido fuertes costos: violaciones a los derechos humanos, mutilaciones oculares a cientos de manifestantes, heridos diarios por las fuerzas públicas y enfrentamientos cotidianos, entre otros. Por lo anterior, este artículo se preguntó cómo reaccionaron los museos y espacios culturales cercanos a la zona cero -en términos de medidas, acciones y respuestas- frente al desarrollo de las marchas, protestas y acontecimientos del estallido social en sus territorios. Con el fin de establecer insumos críticos para pensar las políticas culturales en tiempos de crisis, aquí se propuso sistematizar los aprendizajes organizacionales y discursivos de ellos durante ese escenario.

En cuanto esferas culturales deliberativas, los museos y espacios culturales cumplen un papel clave en la autodescripción y reflexión de las sociedades. A pesar de los aspectos críticos del concepto de esfera pública (Hofmann, 2017) -debido a su normatividad política y la complejidad de la exigencia de reciprocidad 
igualitaria en entornos de alta desigualdad como en Chile y, en general, en América Latina-, nos ayuda a pensar la deliberación pública desde la ciudadanía en contextos de crisis. Y esto quedó en evidencia en este estudio. A partir del estallido social de octubre de 2019, y con base en las dimensiones definidas en la investigación, las respuestas y acciones de estos espacios culturales fueron disímiles según sus peculiaridades, tamaños y dependencias administrativas. Con todo, se pudo advertir que los espacios culturales y museos de dependencia pública experimentaron un desfase de sus capacidades de procesar su entorno/ territorio. Aunque los trabajadores y equipos profesionales expresaron apoyo y soporte al estallido social, las autoridades superiores favorecieron una posición de neutralidad y clausura operativa. Por el contrario, los espacios culturales independientes y los museos privados lograron un trabajo territorial y creativo de mayor profundidad y vinculación con sus comunidades históricas (públicos) y con los habitantes-manifestantes contingentes del territorio.

Por último, fue posible concluir que los distintos museos y espacios culturales cumplen su función de esferas culturales deliberativas en diferentes formas: unos estableciendo un vínculo directo con el territorio y la resistencia, algunos resguardando los rayados como discursos de la resistencia y otros como espacios tradicionales de resguardo del patrimonio. En su diversidad de acciones, todos se inscribieron como esferas públicas deliberativas, pero con márgenes disímiles de rendimiento político-cultural. La lección principal de esta investigación apunta que, en un contexto de crisis social, como el estallido social de octubre de 2019 , los museos y espacios culturales pueden servir como agentes reflexivos y patrocinadores de las demandas sociales. Pero también pueden operar como agentes aparentemente neutrales que los hacen distanciarse del conflicto contingente. Y, por ende, alejarse de su misión de esferas culturales deliberativas.

\section{Fuentes}

Alegría, Luis

2019 Historia, museos y patrimonio. Discursos, representaciones y prácticas de un campo en construcción, Chile 1830-1930, Servicio Nacional de Patrimonio Cultural, Santiago de Chile.

Araujo, Kathya

2009 Habitar lo social: usos y abusos en la vida cotidiana en el Chile actual, Lom, Santiago de Chile.

Araujo, Kathya

2016 El miedo a los subordinados. Una teoría de la autoridad, Lom, Santiago de Chile.
Atria, Fernando

2017 La constitución tramposa, Lom, Santiago de Chile.

BARRETT, JENNIFER

2012 Museums and the Public Sphere, Wiley-Blackwell, Oxford.

BARROS, ROBERT

2002 Constitutionalism and Dictatorship: Pinochet, the Junta, and the 1980 Constitution, Cambridge University Press, Cambridge.

Bellei, Cristián y CRistian Cabalin

2013 "Chilean student movements: Sustained struggle to transform a market-oriented educational system", en Current Issues in Comparative Education, vol. 15, núm. 2, pp. 108-123.

BennetT, Tony

1995 The Birth of the Museum. History, Theory, Politics, Routledge, Londres.

Bennett, Tony

2005 "Civic laboratories. Museums, cultural objecthood and the governance of the social", en Cultural Studies, vol. 19, núm. 5, pp. 521 547, DOI: $10.1080 / 09502380500365416$.

Cabalin, Cristian

2012 "Neoliberal education and student movements in Chile: inequalities and malaise", en Policy Futures in Education, vol. 10, núm. 2, pp. 219-228.

CAstilla, AmÉrico (COMP.)

2010 El museo en escena. Política y cultura en América Latina, Paidós, Buenos Aires.

Collier, Simon y William Sater

2004 A History of Chile, 1808-2002, Cambridge University Press, Cambridge.

Collins, Cath, Katherine Hite

y AlfRedo JoignANT

2013 The Politics of Memory in Chile. From Pinochet to Bachelet, Lynne Rienner, Colorado y Londres.

Donoso, SofíA

2013 "Dynamics of change in Chile: Explaining the emergence of the 2006 'Pingüino' movement”, en Journal of Latin American Studies, vol. 45, núm. 1, pp. 1-29.

Garcés, Mario

2019 "October 2019: Social uprising in neoliberal Chile", en Journal of Latin American Cultural Studies, vol. 28, núm. 3, pp. 483-491, DOI: $10.1080 / 13569325.2019 .1696289$.

Garcés, Mario

2020 Estallido social y una nueva Constitución para Chile, Lom, Santiago de Chile.

Garretón, Manuel Antonio

1996 "El segundo gobierno democrático en Chile. ¿De la transición y consolidación a la profundización democrática?", en Revista Mexicana de Sociología, vol. 58, núm. 1. pp. 121-132.

Garretón, Manuel Antonio

2003 Incomplete Democracy. Political Democratization in Chile and Latin America, The University of North Carolina Press, Chapel Hill y Londres.

Garretón, Manuel Antonio (coord.)

2016 La gran ruptura. Institucionalidad política $y$ actores sociales en el Chile del siglo XXI, Lom, Santiago de Chile.

Gray, Clive

2015 The Politics of Museums, Palgrave-Macmillan, Londres. 
Guardiola-Rivera, Óscar

2013 Story of a Death Foretold: The Coup against Salvador Allende, 11 September 1973. Bloomsbury, Londres.

Han, Clara

2012 Life in Debt: Times of Care and Violence in Neoliberal Chile, University of California Press, Berkeley.

HASLAM, JoNATHAN

2005 The Nixon Administration and the Death of Allende's Chile: A Case of Assisted Suicide, Verso, Londres.

Hofmann, Michael

2017 Habermas's Public Sphere: A Critique, Fairleigh Dickinson University Press, Lanham.

Jocelyn-Holt, Alfredo

2001 El Chile perplejo. Del avanzar sin transar al transar sin parar, Planeta, Santiago de Chile.

LARRAÍn, JORGE

2001 Identidad chilena, Lom, Santiago de Chile.

Mayol, Alberto

2012 El derrumbe del modelo: La crisis de la economía de mercado en el Chile contemporáneo, Lom, Santiago de Chile.

McGuigan, Jim

1996 Culture and the Public Sphere, Routledge, Londres.

Ministerio de las Culturas, las Artes

y el Patrimonio de Chile

2019 Estudio Espacios Culturales de Chile y sus Públicos, Ministerio de las Culturas, las Artes y el Patrimonio de Chile-Departamento de Es-

Moulian, Tomás tudios, Santiago de Chile.

1997 Chile: anatomía de un mito, Lom, Santiago de Chile.

Observatorio de Políticas Culturales

2019 Situación de los museos en Chile, Subdirección Nacional de Museos, Santiago de Chile.

Pinochet, Carla

2016 Derivas críticas del museo en América Latina, Siglo xxi Editores, México.

PNUD

2002 Nosotros los chilenos: un desafío cultural, Programa de las Naciones Unidas para el Desarrollo, Santiago de Chile.

PNUD

2015 Desarrollo humano en Chile. Los tiempos de la politización, Programa de las Naciones Unidas para el Desarrollo, Santiago de Chile.
PNUD

2020 Diez años de auditoría a la democracia: antes del estallido, Programa de las Naciones Unidas para el Desarrollo, Santiago de Chile.

QURESHI, LuBNA

2009 Nixon, Kissinger, and Allende: U.S. Involvement in the 1973 Coup in Chile, Lexington Books, Lanham y Plymouth.

Ruiz, CARLOS

2015 De nuevo la sociedad, Lom, Santiago de Chile.

Sehnbruch, Kirsten y Peter Siavelis (eds.)

2014 Democratic Chile. The Politics and Policies of a Historic Coalition, 1990-2010, Lynne Rienner, Colorado y Londres.

SOLIMANO, ANDRÉs

2012 Chile and The Neoliberal Trap. The Post-Pinochet Era, Cambridge University Press, Cambridge.

Somma, Nicolás, Matías Bargsted,

Rodolfo Disi Pavlic y Rodrigo M. Medel

2020 "No water in the oasis: the Chilean Spring of 2019-2020", en Social Movement Studies, DOI: 10.1080/14742837.2020.1727737.

Subdirección Nacional de Museos

2015 "Antecedentes de una política de museos para Chile", en Museos, núm. 34, pp. 4-37.

Subercaseaux, Bernardo

2011 Historia de las ideas y de la cultura en Chile, 3 vols., Editorial Universitaria, Santiago de Chile.

TAYLOR, MARCUS

2006 From Pinochet to the 'Third Way': Neoliberalism and Social Transformation in Chile, Pluto, Londres.

UgGla, FredriK

2005 "For a few senators more? Negotiating constitutional changes during Chile's transition to democracy", en Latin American Politics \& Society, vol. 47, núm. 2, pp. 51-75.

URIZAR, GaBriEla

2012 "Estado y museos nacionales en Chile durante el siglo XIx. Representación de una nación en construcción", en Boletín Americanista, año 62, núm. 65, pp. 211-229.

Villalobos-Ruminott, Sergio

2012 "The Chilean winter", en Radical Philosophy, núm. 171, pp. 11-15.

ZERÁN, FARIDE (ED.)

2019 Mayo feminista. La rebelión contra el patriarcado, Lom, Santiago de Chile. 


\section{Anexo 1}

Museos y espacios culturales de la muestra

\begin{tabular}{|c|c|c|c|}
\hline $\begin{array}{l}\text { Número } \\
\text { identificador }\end{array}$ & $\begin{array}{l}\text { Dependencia } \\
\text { administrativa del espacio } \\
\text { cultural y/o museo }\end{array}$ & $\begin{array}{l}\text { Tamaño según equipo de trabajo } \\
\text { (pequeña, menos de } 5 \text { personas; media- } \\
\text { na, entre } 5 \text { y } 20 \text { personas; grande, } \\
20 \text { personas o más) }\end{array}$ & $\begin{array}{l}\text { Principal área } \\
\text { de trabajo cultural }\end{array}$ \\
\hline 1 & Pública del Estado & Grande & $\begin{array}{l}\text { Miscelánea (cine, artes } \\
\text { visuales) }\end{array}$ \\
\hline 2 & $\begin{array}{l}\text { Independiente - Organización } \\
\text { de derecho privado sin fines de } \\
\text { lucro }\end{array}$ & Pequeña & Artes visuales \\
\hline 3 & $\begin{array}{l}\text { Independiente - Organización } \\
\text { de derecho privado sin fines de } \\
\text { lucro }\end{array}$ & Pequeña & Teatro \\
\hline 4 & Pública del Estado & Pequeña & Artes visuales \\
\hline 5 & $\begin{array}{l}\text { Independiente - Organización } \\
\text { de derecho privado sin fines de } \\
\text { lucro }\end{array}$ & Grande & $\begin{array}{l}\text { Miscelánea (teatro, } \\
\text { danza, artes visuales, } \\
\text { música) }\end{array}$ \\
\hline 6 & Universitaria pública & Mediana & Artes visuales \\
\hline 7 & Universitaria pública & Pequeña & Histórico \\
\hline 8 & Universitaria pública & Grande & Música \\
\hline 9 & Pública del Estado & Grande & Artes visuales \\
\hline 10 & Pública del Estado & Mediana & Histórico \\
\hline 11 & $\begin{array}{l}\text { Independiente - Organización } \\
\text { de derecho privado sin fines de } \\
\text { lucro }\end{array}$ & Mediana & Artes visuales \\
\hline 12 & Pública del Estado & Grande & Histórico \\
\hline 13 & $\begin{array}{l}\text { Independiente - Organización de } \\
\text { derecho privado }\end{array}$ & Mediana & Cine \\
\hline
\end{tabular}

